Supporting information for

\title{
One-dimensional metallic conducting pathway of cyclohexyl-substituted spiro-biphenalenyl neutral radical molecular crystal
}

\author{
Jingsong Huang and Miklos Kertesz* \\ Department of Chemistry, Georgetown University, \\ $37^{\text {th }} \&$ O Street, Washington, DC 20057-1227 \\ [Email: kertesz@georgetown.edu]
}
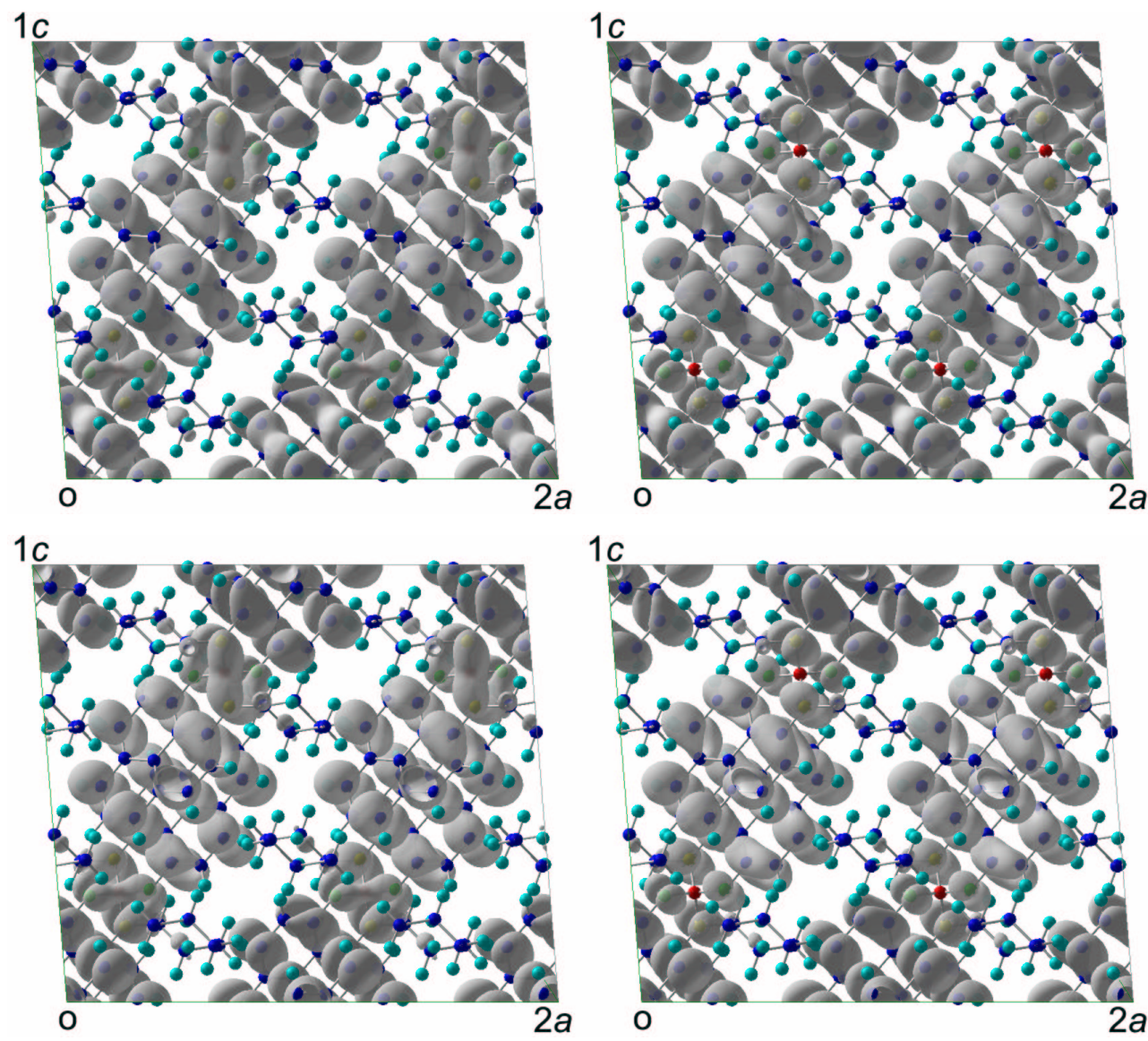

Figure 1S. Electron density isosurfaces of the Kohn-Sham crystal orbitals at the $\Gamma$ point viewed along $\boldsymbol{b}$ for the four bands shown in Fig. 2: Band 1 (upper left), Band 2 (upper right), Band 3 (lower left), Band 4 (lower right). The phase relationships are: spiro inphase with $\pi-\pi$ in-phase, spiro out-of-phase with $\pi-\pi$ in-phase, spiro in-phase with $\pi-\pi$ out-of-phase, and spiro out-of-phase with $\pi-\pi$ out-of-phase, respectively. 

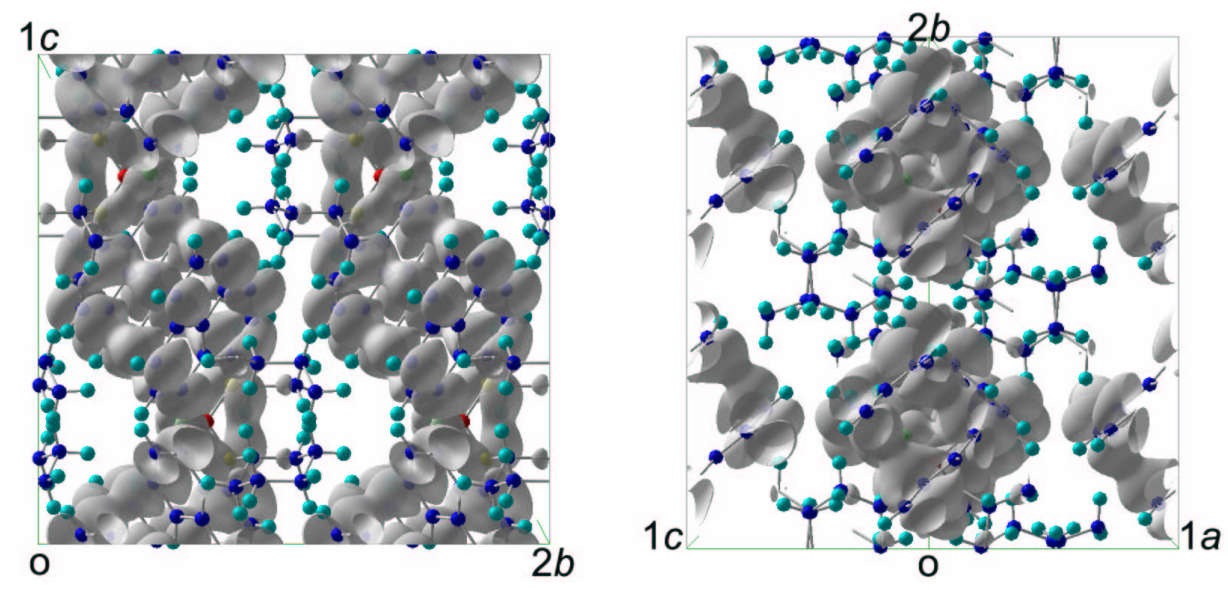

Figure 2S. Electron density isosurfaces of the Kohn-Sham crystal orbital for the second band at the X point viewed down $\boldsymbol{a}$ (left) and down the $\pi$-chain (right), showing the onedimensional conducting pathway along the $[101] \pi$-chain.

Table 1S. Total energy, the level splittings due to spiro-conjugation and the corresponding effective resonance integrals $\beta_{\mathrm{s}}$ for monomer $\mathbf{5}$ calculated with PW91PW91/6-31G* using different charges and multiplicities. For open shell cases, there are two values available due to different $\alpha$ and $\beta$ orbital energies.

\begin{tabular}{|c|c|c|c|c|c|c|}
\hline Charge & Multiplicity & $\begin{array}{c}\text { Total Energy } \\
\text { (Hartree) }\end{array}$ & \multicolumn{2}{|c|}{$\begin{array}{c}\text { Level splittings } \\
(\mathrm{eV})\end{array}$} & \multicolumn{2}{c|}{$\begin{array}{c}\text { Resonance integrals } \\
\beta_{\mathrm{s}}(\mathrm{eV})^{\mathrm{a}, \mathrm{b}}\end{array}$} \\
\hline & & & $\alpha$ orbital & $\beta$ orbital & $\alpha$ orbital & $\beta$ orbital \\
\hline 0 & 2 & -1753.54359558 & 0.395 & 0.364 & 0.197 & 0.182 \\
\hline 1 & 1 & -1753.37771272 & 0.385 & -- & 0.192 & -- \\
\hline-1 & 1 & -1753.58887206 & 0.372 & -- & 0.186 & -- \\
\hline-1 & 3 & -1753.58284022 & 0.397 & 0.369 & 0.198 & 0.184 \\
\hline
\end{tabular}

${ }^{\mathrm{a}} \beta_{\mathrm{s}}$ is half of the level splitting. See Huang, J.; Kertesz, M. [ J. Chem. Phys. 2005, 122, 234707] for this approach in calculating effective resonance (transfer) integrals.

${ }^{\mathrm{b}}$ Average value for $\beta_{\mathrm{s}}$ is $0.190 \mathrm{eV}$. 
Table 2S. Coordinates used for the single-point molecular calculations.

\begin{tabular}{|c|c|c|c|c|c|c|c|}
\hline B & 2.0367 & 5.7939 & 4.2101 & & & & \\
\hline $\mathrm{O}$ & 3.2104 & 4.9182 & 4.3162 & $\mathrm{O}$ & 0.8629 & 4.9182 & 4.104 \\
\hline $\mathrm{N}$ & 1.8554 & 6.6511 & 5.4815 & $\mathrm{~N}$ & 2.2179 & 6.6511 & 2.9386 \\
\hline $\mathrm{C}$ & 4.0583 & 4.9095 & 5.3417 & $\mathrm{C}$ & 0.0151 & 4.9095 & 3.0784 \\
\hline $\mathrm{C}$ & 5.1825 & 4.0769 & 5.2592 & $\mathrm{C}$ & -1.1092 & 4.0769 & 3.1609 \\
\hline $\mathrm{C}$ & 6.0739 & 4.0048 & 6.2848 & $\mathrm{C}$ & -2.0006 & 4.0048 & 2.1353 \\
\hline $\mathrm{C}$ & 5.9117 & 4.7749 & 7.4603 & $\mathrm{C}$ & -1.8383 & 4.7749 & 0.9599 \\
\hline $\mathrm{C}$ & 6.7978 & 4.7108 & 8.5532 & $\mathrm{C}$ & -2.7244 & 4.7108 & -0.133 \\
\hline $\mathrm{C}$ & 6.5962 & 5.4546 & 9.6865 & $\mathrm{C}$ & -2.5228 & 5.4546 & -1.2664 \\
\hline $\mathrm{C}$ & 5.494 & 6.2986 & 9.7775 & $\mathrm{C}$ & -1.4207 & 6.2986 & -1.3573 \\
\hline $\mathrm{C}$ & 4.5882 & 6.4138 & 8.7182 & $\mathrm{C}$ & -0.5149 & 6.4138 & -0.2981 \\
\hline $\mathrm{C}$ & 3.4492 & 7.256 & 8.7603 & $\mathrm{C}$ & 0.6242 & 7.256 & -0.3402 \\
\hline $\mathrm{C}$ & 2.5574 & 7.3501 & 7.7381 & $\mathrm{C}$ & 1.5159 & 7.3501 & 0.682 \\
\hline $\mathrm{C}$ & 2.7045 & 6.5878 & 6.5391 & $\mathrm{C}$ & 1.3688 & 6.5878 & 1.8811 \\
\hline $\mathrm{C}$ & 3.8529 & 5.7245 & 6.4633 & $\mathrm{C}$ & 0.2205 & 5.7245 & 1.9568 \\
\hline $\mathrm{C}$ & 4.7808 & 5.6418 & 7.5428 & $\mathrm{C}$ & -0.7075 & 5.6418 & 0.8774 \\
\hline $\mathrm{C}$ & 0.5337 & 7.3466 & 5.4243 & $\mathrm{C}$ & 3.5396 & 7.3466 & 2.9959 \\
\hline $\mathrm{C}$ & -0.4738 & 6.8059 & 6.4397 & $\mathrm{C}$ & 4.5472 & 6.8059 & 1.9804 \\
\hline $\mathrm{C}$ & -1.7901 & 7.5471 & 6.2292 & $\mathrm{C}$ & 5.8634 & 7.5471 & 2.1909 \\
\hline $\mathrm{C}$ & -1.6319 & 9.0593 & 6.2545 & $\mathrm{C}$ & 5.7052 & 9.0593 & 2.1657 \\
\hline $\mathrm{C}$ & -0.6353 & 9.5288 & 5.234 & $\mathrm{C}$ & 4.7086 & 9.5288 & 3.1862 \\
\hline $\mathrm{C}$ & 0.7145 & 8.8588 & 5.463 & $\mathrm{C}$ & 3.3588 & 8.8588 & 2.9572 \\
\hline $\mathrm{H}$ & 5.3224 & 3.5608 & 4.4863 & $\mathrm{H}$ & -1.249 & 3.5608 & 3.9339 \\
\hline $\mathrm{H}$ & 6.8136 & 3.4298 & 6.2107 & $\mathrm{H}$ & -2.7402 & 3.4298 & 2.2094 \\
\hline $\mathrm{H}$ & 7.5458 & 4.1437 & 8.5044 & $\mathrm{H}$ & -3.4725 & 4.1437 & -0.0842 \\
\hline $\mathrm{H}$ & 7.2031 & 5.3957 & 10.4023 & $\mathrm{H}$ & -3.1298 & 5.3957 & -1.9821 \\
\hline $\mathrm{H}$ & 5.3551 & 6.7971 & 10.5622 & $\mathrm{H}$ & -1.2818 & 6.7971 & -2.1421 \\
\hline $\mathrm{H}$ & 3.3028 & 7.7739 & 9.5316 & $\mathrm{H}$ & 0.7706 & 7.7739 & -1.1115 \\
\hline $\mathrm{H}$ & 1.8245 & 7.9321 & 7.824 & $\mathrm{H}$ & 2.2489 & 7.9321 & 0.5961 \\
\hline $\mathrm{H}$ & 0.1568 & 7.1409 & 4.5334 & $\mathrm{H}$ & 3.9166 & 7.1409 & 3.8867 \\
\hline $\mathrm{H}$ & -0.6027 & 5.8432 & 6.3067 & $\mathrm{H}$ & 4.676 & 5.8432 & 2.1135 \\
\hline $\mathrm{H}$ & -0.1459 & 6.9518 & 7.3508 & $\mathrm{H}$ & 4.2193 & 6.9518 & 1.0694 \\
\hline $\mathrm{H}$ & -2.1712 & 7.2807 & 5.367 & $\mathrm{H}$ & 6.2445 & 7.2807 & 3.0531 \\
\hline $\mathrm{H}$ & -2.421 & 7.2807 & 6.9298 & $\mathrm{H}$ & 6.4943 & 7.2807 & 1.4904 \\
\hline $\mathrm{H}$ & -1.3375 & 9.3389 & 7.147 & $\mathrm{H}$ & 5.4109 & 9.3389 & 1.2731 \\
\hline $\mathrm{H}$ & -0.534 & 10.5012 & 5.2963 & $\mathrm{H}$ & 4.6074 & 10.5012 & 3.1239 \\
\hline $\mathrm{H}$ & -0.9613 & 9.3142 & 4.3347 & $\mathrm{H}$ & 5.0346 & 9.3142 & 4.0855 \\
\hline $\mathrm{H}$ & 1.3461 & 9.1358 & 4.7658 & $\mathrm{H}$ & 2.7272 & 9.1358 & 3.6543 \\
\hline $\mathrm{H}$ & 1.0771 & 9.1287 & 6.332 & $\mathrm{H}$ & 2.9962 & 9.1287 & 2.0882 \\
\hline $\mathrm{H}$ & -2.4995 & 9.7399 & 6.0777 & $\mathrm{H}$ & 6.5728 & 9.7399 & 2.3425 \\
\hline
\end{tabular}

The set of coordinates used for the solid-state calculations are taken from the published X-ray structure (see Ref. 6). 


\section{Derivation of energy expressions for crystal orbitals at the $\Gamma$ point}

As shown in Fig. 3, there are two unique effective transfer integrals along the chain. Therefore, we can assume that the unit cell consists of one molecule. The $k$-dependent Hamiltonian matrix for the 1-D periodic Hückel model is $\left(\begin{array}{cc}\alpha & \beta_{s}+\beta_{\pi} e^{-i k} \\ \beta_{s}+\beta_{\pi} e^{i k} & \alpha\end{array}\right) \cdot{ }^{14}$ Solving $\underline{\underline{H}}(k) \underline{c}(k)=\varepsilon(k) \underline{c}(k)$, one obtains the following eigenvalues for the two bands: $\varepsilon(k)=\alpha \pm \sqrt{\beta_{\pi}{ }^{2}+\beta_{s}{ }^{2}+2 \beta_{\pi} \beta_{s} \cos (k)}$. At the Brillouin zone edge of the chain, $k$ 's values are 0 and $\pi$. Setting $\alpha=0$, the energies are therefore $\varepsilon(0)= \pm\left|\beta_{\pi}+\beta_{s}\right|$ and $\varepsilon(\pi)= \pm\left|\beta_{\pi}-\beta_{s}\right|$.

We define the electronic interaction through spiro-conjugation and $\pi-\pi$ overlap shown in Fig. 3 by out-of-phase orbital combination of adjacent phenalenyl moieties so that $\beta_{\mathrm{s}}$ and $\beta_{\pi}$ are positive. (This means that a negative sign in front of $\beta_{\mathrm{s}}$ and $\beta_{\pi}$ would indicate in-phase orbital combination of adjcent phenalenyl moieties.) At $k=0$, the lowest energy level is $-\beta_{\pi}-\beta_{\mathrm{s}}$, and the highest energy level is $\beta_{\pi}+\beta_{\mathrm{s}}$. The relative magnitudes of $\beta_{\pi}$ and $\beta_{\mathrm{s}}$ determine the order of the middle two energy levels with $k=\pi$. In this case, $\beta_{\mathrm{s}}$ must be smaller than $\beta_{\pi}$ in order to reproduce the phase relationship shown in Fig. 1S. The middle two energy levels are therefore $-\beta_{\pi}+\beta_{\mathrm{s}}$ and $\beta_{\pi}-\beta_{\mathrm{s}}$, in the order of increasing energy.

This treatment assumes there is one molecule in the unit cell. In the 3-D crystal structure, there are two molecules per unit cell. Doubling the unit cell simply "backfolds" the bands, so that the four levels now correspond to the $\Gamma$ point with wave vector $k=0$ in the reduced Brillouin zone. ${ }^{14}$ Thus, we can compare these energy expressions with the four crystal orbital energies at the $\Gamma$ point in Fig. 2.

The signs in these energy expressions indicate that the phase relationships for the four levels are, in the order of increasing energy: spiro in-phase with $\pi-\pi$ in-phase, spiro outof-phase with $\pi-\pi$ in-phase, spiro in-phase with $\pi-\pi$ out-of-phase, and spiro out-of-phase with $\pi-\pi$ out-of-phase, respectively, in agreement with those shown in Fig. 1S. 


\section{Author list truncated:}

(15) Frisch, M. J.; Trucks, G. W.; Schlegel, H. B.; Scuseria, G. E.; Robb, M. A.; Cheeseman, J. R.; Zakrzewski, V. G.; Montgomery, J. A., Jr.; Stratmann, R. E.; Burant, J. C.; Dapprich, S.; Millam, J. M.; Daniels, A. D.; Kudin, K. N.; Strain, M. C.; Farkas, O.; Tomasi, J.; Barone, V.; Cossi, M.; Cammi, R.; Mennucci, B.; Pomelli, C.; Adamo, C.; Clifford, S.; Ochterski, J.; Petersson, G. A.; Ayala, P. Y.; Cui, Q.; Morokuma, K.; Malick, D. K.; Rabuck, A. D.; Raghavachari, K.; Foresman, J. B.; Cioslowski, J.; Ortiz, J. V.; Stefanov, B. B.; Liu, G.; Liashenko, A.; Piskorz, P.; Komaromi, I.; Gomperts, R.; Martin, R. L.; Fox, D. J.; Keith, T.; Al-Laham, M. A.; Peng, C. Y.; Nanayakkara, A.; Gonzalez, C.; Challacombe, M.; Gill, P. M. W.; Johnson, B. G.; Chen, W.; Wong, M. W.; Andres, J. L.; Head-Gordon, M.; Replogle, E. S.; Pople, J. A. 